\title{
Literature contributions of a paediatric cardiologist to adult congenital heart disease - Part I
}

\author{
P. Syamasundar Rao* \\ Professor of Pediatrics \& Medicine, Emeritus Chief of Pediatric Cardiology, University of Texas at Houston, McGovern Medical School, USA
}

\begin{abstract}
The author's contributions with regard to aorto-pulmonary communications, namely patent ductus arteriosus and aortopulmonary window were reviewed. Successful closure with the buttoned device with excellent immediate and follow-up results in single adult cases as well in large international clinical trial were documented. Now
\end{abstract} that the buttoned device is not available for clinical use, the author utilizes other devices, namely, Gianturco coils and Amplatzer devices instead.

\section{Introduction}

The majority of the cardiologists in the US were trained to address coronary artery, myocardial and valvular heart disease until recently, without much experience with congenital heart disease (CHD). As a result, most cardiologists do not have much interest in attending to CHD; furthermore, they are very active in treating patients with coronary artery disease. Consequently, the author was called upon to consult when CHD was suspected in adult patients from the beginning of his first appointment at the Medical College of Georgia in 1972. The same theme continued during his tenure at the University of Wisconsin, the St. Louis University, and the University of Texas. Furthermore, the author was involved in performing catheter interventional procedures for non-coronary congenital heart problems in adults at the last three of these institutions. In this review, the author reviews his contributions to the literature regarding adult CHDs [1-13]. But, it should be mentioned that some institutions around the world have tried to specifically address the problems associated with adult CHD; these to the author's knowledge include the grown-up congenital heart disease $(\mathrm{GUCH})$ program initiated by Dr. Jane Summerville in London, England, the adult congenital heart program organized by Dr. Joseph Perloff in Philadelphia, PA (which later moved to Los Angeles, CA), and the adult heart program initiated by Dr. Carol Warner and others at Rochester, MN. Currently, several programs are being developed around the country to address CHD in adult subjects.

The advances in perinatal cardiac care, non-invasive and invasive diagnosis, anaesthesia, surgical and transcatheter therapeutic techniques and post-operative care have resulted in survival of a larger number of these babies; nearly $85 \%$ to $90 \%$ of babies born with CHD are likely to reach adulthood [14]. At this time, there are more patients over the age of 20 with CHD than infants, children and adolescents combined. It is estimated that the patients with adult $\mathrm{CHD}$ are growing at a rate of 5\% per year and there are more than one million adults with $\mathrm{CHD}$ in the US alone. One-third of these are complex CHD, a third are moderately severe defects and the final third are simple CHDs. Given this background, the author plans to summarize his contributions to adult CHD. In this Part I, aorto-pulmonary communications (patent ductus arteriosus and aorto-pulmonary window) will be addressed.

\section{Percutaneous closure of patent ductus arteriosus}

The author has performed percutaneous closure of patent ductus arteriosus (PDA) in adults and presented the data in peer-reviewed publications $[1,4]$. Subsequent to the successful use of the PDA buttoned device in experimental animal models by Sideris and his colleagues [15], and excellent results with PDA buttoned device closure in children [16,17], the procedure was undertaken in an adult patient [1].

\section{First clinical application in an adult patient}

A 65-year-old woman with complaints of shortness of breath and palpitations and New York Heart Association (NYHA) class II symptoms along with long-standing bronchial asthma with mild obstructive lung disease was referred to us for management. On physical examination, a grade III/VI continuous murmur was heard at the upper left sternal border. Electrocardiogram (ECG) revealed a left ventricular volume overload pattern. Echo-Doppler studies established the diagnosis of PDA with normal pulmonary artery pressure. In view of her age and other problems cited above, percutaneous closure of the PDA was suggested. Institutional Review Board (IRB) approval from the hospital was obtained and informed consent was secured from the patient. Cardiac surgical stand-by was arranged. Cardiac catheterization revealed a step up in $\mathrm{O} 2$ saturation from the right ventricle to the pulmonary artery with a calculated pulmonary systemic flow ratio (Qp:Qs) of 1.5:1.0. The pulmonary artery pressure was 25/10 with a mean of $15 \mathrm{mmHg}$. Aortogram in the left anterior oblique view revealed a moderate PDA (Figure 1). Coronary arteriography, left ventricular wall motion, and ejection fraction were normal. A 20 $\mathrm{mm}$ adjustable buttoned device was implanted across the PDA (Figure 1b) via a $8-\mathrm{F}$ sheath in the manner described previously $[1,16,17]$.

${ }^{*}$ Correspondence to: P Syamasundar Rao, Professor of Pediatrics \& Medicine, Emeritus Chief of Pediatric Cardiology, University of Texas at Houston, McGovern Medical School, Houston, Texas, USA, Tel: 832-2601050, E-mail: P.Syamasundar.Rao@uth.tmc.edu

Key words: patent ductus arteriosus, percutaneous occlusion, aortopulmonary window, residual shunts, buttoned device, gianturco coils, amplatzer devices

Received: June 22, 2020; Accepted: July 02, 2020; Published: July 06, 2020 


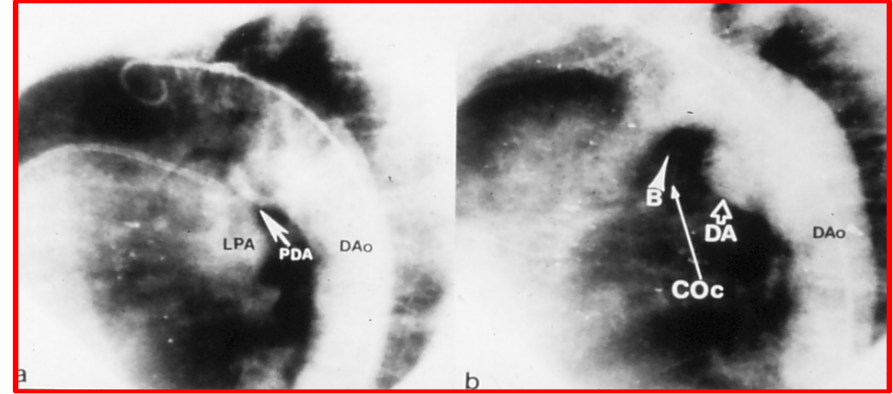

Figure 1. a. Selected cine frame from aortic arch cineangiogram in left anterior oblique view, demonstrating the filling of the pulmonary artery through a moderate-sized patent ductus arteriosus (PDA). b. Aortography 15 minutes following implantation of the buttoned device across the PDA shows complete the occlusion of the left-to-right shunt through ductus. B, button; COc, counter-occluder, DA, ductal ampulla; DAo, descending aorta; LPA, left pulmonary artery. Reproduced from Lochan R, Rao PS, Samal AK, et al., Am Heart J 1994; 127:941-3.

Aortography 15 minutes later (Figure 1b) demonstrated complete occlusion of the PDA. Heparin was administered during the procedure, three doses of cephazolin $(50 \mathrm{mg} / \mathrm{kg})$ were given intravenously, and aspirin at $325 \mathrm{mg}$ daily beginning the morning after the procedure for 3 months to prevent excessive deposition of platelets were undertaken. Echo-Doppler studies next morning showed no evidence of a residual shunt. At 3 months' follow-up, the patient had no symptoms, and had no murmur on auscultation. A chest $\mathrm{x}$-ray showed the device to be in place, and no residual shunt was seen by echo-Doppler study.

This seems to be the first adult case of successful PDA closure with the adjustable buttoned device, following reports of successful closure in children [16,17]. We stated that percutaneous closure with the adjustable buttoned device is a safe, simple, and effective procedure for the closure of PDAs in adults and suggested that long-term follow up data and more experience are necessary before the wider clinical application of this procedure [1]

\section{International study of PDA closure in adults}

Following the successful initial clinical trial in children [16,17] and the successful use in an adult just described [1], a larger international clinical trial was initiated at ten institutions around the world [4]. The number of subjects undergoing buttoned device occlusion of PDA at each these institutions varied between 3 and 23 with a median of 4 . The indications, patient selection, technique of device implantation, and the protocol were described in our prior publication [4].

Study Subjects: During a 40-month period ending in August 1996, 77 patients underwent occlusion of PDA with the buttoned device. One of these patients was included in our prior publication [1]. The ages of the patients varied between 16 and 92 years (median of 52 years). The weights ranged between 29 and $92 \mathrm{~kg}$ with a median of $52 \mathrm{~kg}$.

PDAs: The minimal ductal diameter, as measured on lateral cine-angiographic views, ranged between 2 and $15 \mathrm{~mm}$ (median of 5 $\mathrm{mm}$ ). Eleven of these PDAs were $8 \mathrm{~mm}$ or more in diameter and six were larger than $10 \mathrm{~mm}$. The Qp:Qs was $1.9 \pm 0.5$ (mean $\pm \mathrm{SD}$ ) with a range of 1.3 to 3.3. The protocol for this study was designed before the publication of Krichenko's classification of PDA [18] and therefore, that classification was not used to classify the shapes of the PDA. The PDA was conical in shape in $45(58 \%)$ patients, tubular in $17(22 \%)$, and short in 9 (12\%), and miscellaneous types were found in 3 (4\%) patients. Three (4\%) patients had had a prior Rashkind PDA device occlusion, but still had a residual shunt.
Devices: The buttoned device used in this study is illustrated in Figure 2. $15 \mathrm{~mm}$ devices were used in 21 patients, delivered via $7-\mathrm{F}$ sheaths. $20 \mathrm{~mm}$ devices were used in 42 patients, $25 \mathrm{~mm}$ devices in 8 patients, $30 \mathrm{~mm}$ devices in 3 patients, and $35 \mathrm{~mm}$ devices in three patients. These devices were implanted across the PDA via 8-F sheaths.

Immediate results: Successful device implantation was achieved in $76(98.7 \%)$ of 77 patients. In the lone exception, a $15 \mathrm{~mm}$ device was pulled through the PDA while buttoning. Transcatheter retrieval was accomplished and the patient was sent to elective surgical ligation at the discretion of the primary cardiologist. No other complications were observed. The Qp:Qs decreased from $1.9 \pm 0.5$ to $1.1 \pm 0.2(\mathrm{p}<0.001)$ after device implantation. All types of PDAs, irrespective of the shape (conical, tubular, and short) and length (long or short), and including those with a prior Rashkind device, could be occluded. Both small and large PDAs could be occluded without any problems. Continuous murmurs which were present prior to occlusion were no longer heard in the 76 patients in whom the device was successfully implanted. Echo-Doppler studies revealed effective occlusion, defined as a trivial $(\mathrm{n}=27)$ or absent $(\mathrm{n}=43)$ residual shunt (Table 1$)$, in $70(92 \%)$ of 76

Table 1. Quantification of Residual Ductal Shunt

\begin{tabular}{|l|l|}
\hline Grade & Criteria \\
\hline None & No residual shunt \\
\hline Trivial & $\begin{array}{l}\text { Color Doppler jet width } \leq 1 \mathrm{~mm} \text { at the origin of the shunt } \\
\text { No left ventricular volume overload* }\end{array}$ \\
\hline Small & $\begin{array}{l}\text { Color Doppler jet width of residual shunt between } 1 \text { and } 2 \mathrm{~mm} \\
\text { No left ventricular volume overload* }\end{array}$ \\
\hline Medium & $\begin{array}{l}\text { Color Doppler jet width of residual shunt between } 2 \text { and } 4 \mathrm{~mm} \\
\text { Left ventricular volume overload* may be present }\end{array}$ \\
\hline Large & $\begin{array}{l}\text { Color Doppler jet width of residual shunt }>4 \mathrm{~mm} \\
\text { Left ventricular volume overload* is present }\end{array}$ \\
\hline
\end{tabular}

*Left ventricular volume overload is defined as a left atrium to aortic root ratio $>1.2$ and an enlargement of the left atrium and left ventricle $\left(>95^{\text {th }}\right.$ percentile for age). Reproduced from Rao PS, et al., J Am Coll Cardiol 1999; 33:820-6.

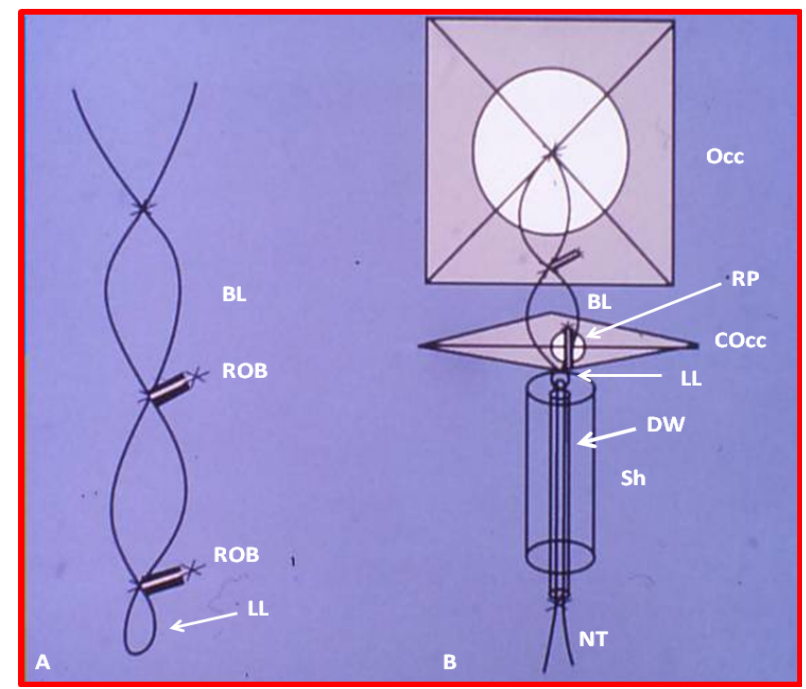

Figure 2. Cartoon of the adjustable buttoned device used for occlusion of patent ductus arteriosus. A. button loop. B. components of the device: occluder (Occ), counter-occluder (COcc) and sheath (Sh). The occluder (Occ) consists of 1/16" polyurethane foam covering an $\mathrm{x}$-shaped Teflon-coated wire skeleton (WS) connected to a buttoned loop (BL). A folded nylon thread (NT) passes through the lower loop (LL) of the BL following passage through a delivery wire (DW) after having its core removed. The counter-occluder (COcc) is made up of a rhomboid-shaped piece of polyurethane foam covering a single-strand Teflon-coated wire. A rubber piece (RP) is sutured into it, forming a buttonhole. The sheath (Sh) tip is shown, through which the folded occluder would pass through. The size of this is either 7F or $8 \mathrm{~F}$. A shows a magnified view of the BL showing the radiopaque spring buttons (ROB). The bottom part is connected to the occluder in the middle and the NT goes through the LL. 
patients. Small $(n=6)$ or trivial $(n=27)$ residual shunts were detected on color flow imaging in 33 of 76 (43\%) successful device implantations. Neither the minimal ductal diameter nor the shape of the ductus had an influence ( $p>0.1$ ) on the prevalence of residual shunts (Figure 3). Methodical two-dimensional (2D) and Doppler interrogation of the descending aorta and left pulmonary artery did not reveal evidence for obstruction in either of these structures.

Follow-up results: Follow-up data were available for review in $61(80 \%)$ of 76 patients, 1 to 48 months (median 24 ) after device implantation. Re-interventions were required in two (3.5\%) patients during follow-up. One patient had a Gianturco coil implanted to treat the residual shunt, which was successful, and the other patient had surgical ligation for the residual shunt with hemolysis, at the discretion of the primary cardiologist. A review of the chest x-rays showed good/ stable device positioning, without fractures of the radiopaque wire components of the device. No incidents of endocarditis or thrombus formation were seen during follow-up. Echo-Doppler studies showed a gradual decrease in the number of patients with residual shunts, with actuarial residual shunt rates of $43 \%, 25 \%, 25 \%, 17 \%, 15 \%, 10 \%$, and $0 \%$ respectively at 1 day, and $1,6,12,24,36$, and 48 months after device implantation (Figure 4). There were no instances of re-canalization, i.e., no reappearance of the shunt after it had been demonstrated closed by color Doppler imaging. No evidence was seen for obstruction, either in the descending aorta or in the left pulmonary artery.

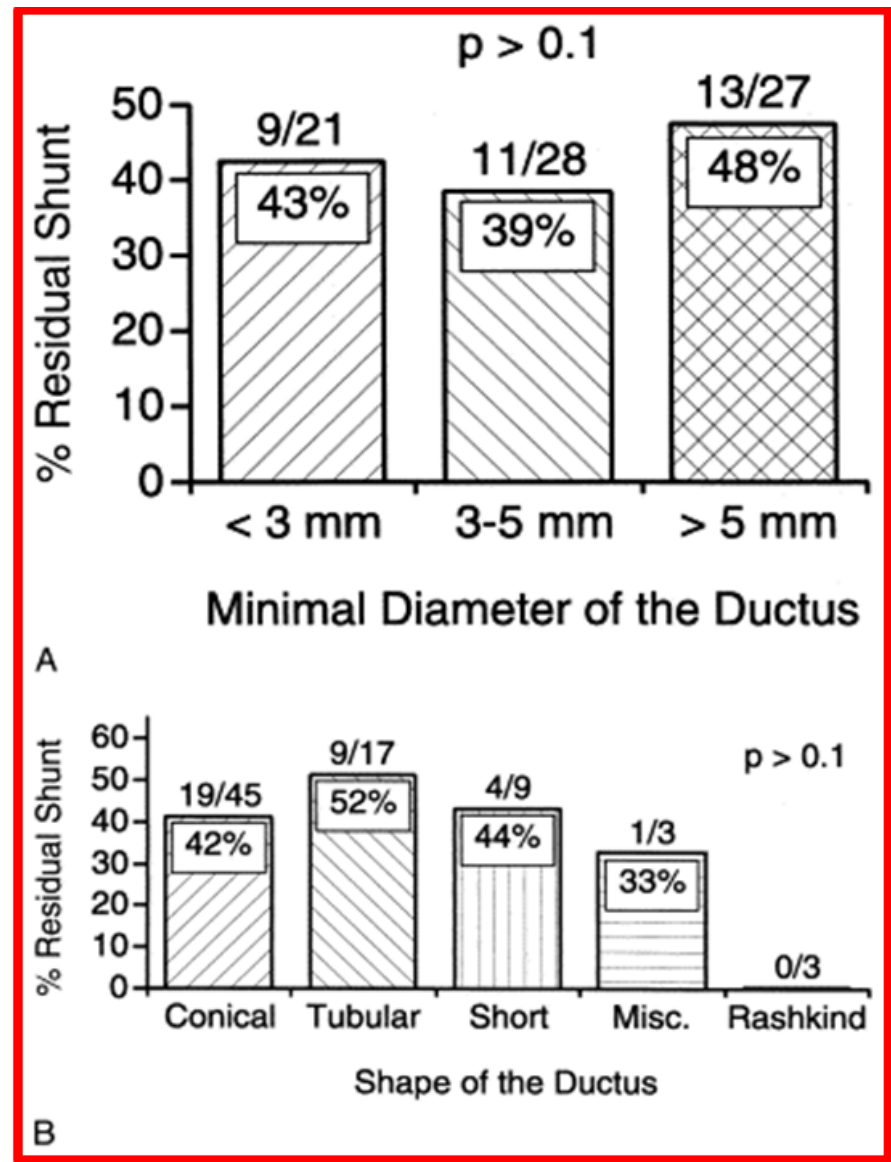

Figure 3. A. Relationship of residual shunt to minimal ductal diameter. Note that there is no significant $(p>0.1)$ difference in the prevalence of residual shunts between various sizes of ductus. B. The relationship between the ductal shape and percentage of residual shunt is shown. Note that there is no significant relationship $(p>0.1)$. The raw numbers are placed at the top of each bar and the percentage residual shunt within the bar. Reproduced from Rao PS, et al., Am J Cardiol 1998; 82:827-9.

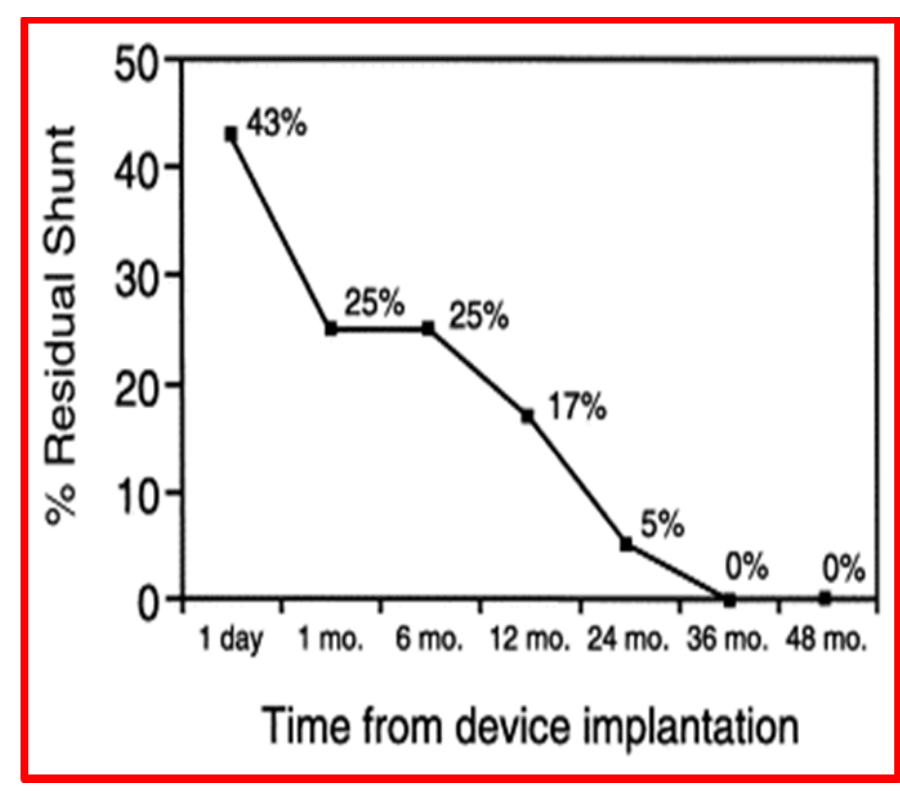

Figure 4. Actuarial residual shunts at varying periods following device implantation Residual shunts were $43 \%, 25 \%, 25 \%, 17 \%, 15 \%, 10 \%$, and $0 \%$ at 1 day, and $1,6,12$, 24, 36, and 48 months, respectively. Reproduced from Rao PS, et al. Am J Cardiol 1998; $82: 827-9$.

In conclusion the findings of the multi-institutional study presented above confirm the feasibility, safety, and effectiveness of buttoned device occlusion of PDAs that was previously shown in studies involving smaller numbers of patients $[1,16,17]$. Buttoned device occlusion is effective irrespective of the shape (conical, tubular or short), diameter (small, medium or large), and length (short or long) of the PDA.

\section{Transcatheter closure of aortopulmonary window}

Aortopulmonary window (APW) is a rare congenital heart defect (CHD) accounting for roughly $0.1 \%$ of all congenital cardiac anomalies [5]. The APW is a defect/communication in the aorto-pulmonary septum and is different from PDA. Several classifications of APW have been described, as reviewed by us [5]. Proximal defects between the ascending aorta and the main pulmonary artery have little or no inferior rim separating the APW from the semilunar valves. Distal defects between the pulmonary artery and the ascending aorta have a well-formed inferior rim but have little superior rim. Defects that are a combination of the above two types with little or no superior and inferior rims are usually very large. Intermediate defects with adequate inferior and superior rims (Figure 5A) are less common. The first three types are not amenable for transcatheter occlusion and require surgery, while the intermediate type may be addressed by transcatheter techniques. We have used the buttoned device described by Sideris [16,19], that was also used for the occlusion of atrial septal defects (ASDs) [20,21], PDAs $[1,16]$, and VSDs [22] to occlude APW [5].

A 27-year-old woman was referred to the author due to her desire to have nonsurgical closure of her APW. Her past history was positive for surgical closure of PDA at the age of one year. She was essentially asymptomatic but had a $3 / 6$ continuous murmur at the left mid-sternal border, bounding pulses, and a well-healed scar from left thoracotomy. Echo-Doppler studies showed a dilated left atrium and left ventricle with a left-to-right shunt between the ascending aorta and proximal main pulmonary artery (PA), suggestive of APW. The Doppler velocity of the shunt jet was $4.5 \mathrm{~m} / \mathrm{s}$, suggesting normal PA pressures. Buttoned device closure of ASDs and PDAs in human subjects was approved 
by the Food and Drug Administration (FDA) with an investigational device exemption (IDE) and by the Institutional Review Board (IRB) at that time. Because of the patient's desire for nonsurgical management of her defect, compassionate use of the buttoned device was undertaken, and informed consent was secured. Cardiac catheterization revealed normal PA pressures $(25 / 12 \mathrm{mmHg})$, a step-up in O2 saturation from the right ventricle $(70 \%)$ to the $\mathrm{PA}(86 \%)$ with a pulmonary-to-systemic flow ratio (Qp:Qs) of 2:1. Selective cineaortography (Figure 5A) confirmed the diagnosis of APW. There was no evidence for a PDA. The APW measured $3.7 \mathrm{~mm}$ in diameter and was positioned in the anterior left aspect of the proximal ascending aorta, $14 \mathrm{~mm}$ away from the origin of the left main coronary artery and $25 \mathrm{~mm}$ away from both the aortic and pulmonary valves.

Heparin was administered intravenously. The APW could not be cannulated anterogradely from the PA, but was entered retrogradely from the ascending aorta with a 4-F Glidecath catheter (MediTech, Watertown, Massachusetts) and a 0.035" Benston wire (Cook, Bloomington, Indiana). The catheter and guide wire were advanced from the main PA to the left PA. The Benston wire was exchanged with a J tipped, 0.035", extra-stiff Amplatz guide wire (Cook) and its tip was positioned in the left PA. A gooseneck snare (Microvena, White Bear Lake, Minnesota) was introduced into the right femoral venous sheath and advanced into the left PA, and the tip of the Amplatz wire was snared and pulled out of the femoral venous sheath. An 8-F delivery sheath (Cook) was then advanced from the femoral venous end of this guide wire rail and its tip positioned in the ascending aorta across the APW.

The square-shaped occluder component of a 15 -mm adjustable buttoned PDA device (Figure 6) was delivered into the aorta under fluoroscopic guidance and the tip of the sheath was pulled back into the PA [5]. Then the single-strand, rhomboid-shaped counter-occluder was delivered into the PA. The occluder and counter-occluder were buttoned across the APW (Figure 5B). The delivery wire was disconnected and withdrawn, as was the sheath. An aortic root angiogram was repeated, and this revealed minimal, if any, filling of the pulmonary artery, most likely related to the porosity of the polyurethane material of the device (Figure 5C). The coronary arteries were opacified normally without any evidence for obstruction. Also, there was no evidence for aortic or pulmonary valve insufficiency. The continuous murmur was no longer heard and a repeat echo-Doppler study on the morning after the procedure demonstrated a small color flow disturbance in the PA. However, this residual shunt was not detected on echo-Doppler studies performed one and six months later. The patient remained asymptomatic and cardiovascular examination revealed normal findings without a murmur during follow-up.

This report [5] documented the first successful percutaneous closure of an APW with the buttoned device in an adult patient. Prior to the publication of our report, three other patients [5] were reported to have transcatheter occlusion of APW. The first report of transcatheter closure of APW was by Stamato and colleagues [23]; they used a Rashkind double umbrella PDA device and successfully occluded a post-operative residual APW. Subsequently Tulloh and associated successfully occluded a native APW in an infant with a double umbrella device [24]. Subsequent to these reports, a number of other investigators, as referenced elsewhere [5], utilized the Amplatzer Duct Occluder (ADO), Amplatzer Septal Occluder (ASO), Amplatzer Muscular VSD Occluder, Amplatzer Perimembranous VSD Occluder, and Shen-Zhen Lifetech Scientific Inc's Muscular VSD Occluder devices to transcatheter occlude APWs [5]. We observed that the intermediate type of APW in our patient was suitable for percutaneous occlusion

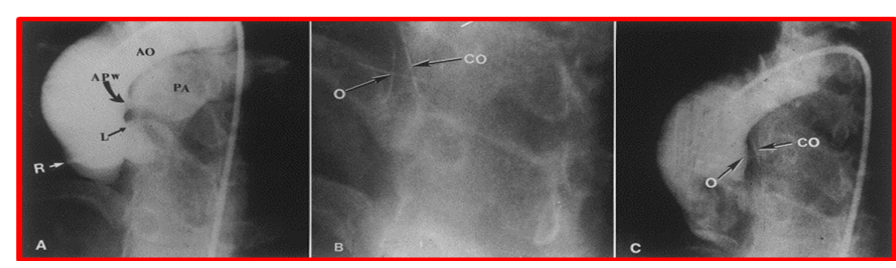

Figure 5. A. Selected frame from a cineaortogram in the left anterior oblique projection, demonstrating the location, size, and shape of the aortopulmonary window (APW). There is dense filling of the pulmonary artery (PA). The distance between the defect and the left coronary artery (L) is foreshortened in this view but is outlined better on the lateral projection (not included). B. The occluder $(\mathrm{O})$ and counter occluder $(\mathrm{CO})$ of the buttoned device are shown after their buttoning across the defect. C. Repeat aortic root angiogram in the same view as in A after the buttoned device placement, showing minimal, if any, filling of the pulmonary artery. AO, aorta; R, right coronary artery. Reproduced from Jureidini SB, Spadaro JJ, Rao PS, Am J Cardiol 1998; 81:371-2.

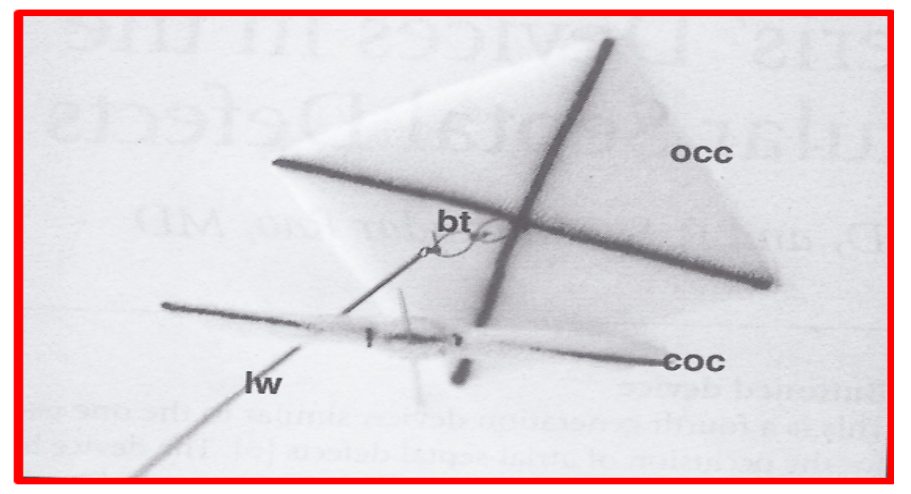

Figure 6. Photograph of a buttoned device used for occlusion of aorto-pulmonary window. The square-shaped occluder (OCC) with the button loop (bt) and loading wire (lw) attached to it are shown. The single-strand counter-occluder (COC) is also pictured beside the OCC. This is similar to the adjustable buttoned device used for closure of patent ductus arteriosus, and the fourth-generation buttoned device used for occlusion of atrial septal defects. Reproduced from Sideris EB, Haddad J, Rao PS, Current Intervent Cardiol Reports 2001; 3:349-53.

because it was not large and its location was away from the origin of the left coronary artery, pulmonary valve, and right and left PAs. Proximal, distal and combined APWs are larger and are without adequate rims and may not be suitable for transcatheter occlusion [5].

In conclusion, our case illustrated that it is feasible to occlude intermediate types of APW with the buttoned device percutaneously. This approach appears promising and may prove to be a useful alternative to surgical therapy if future attempts provide successful results similar to our case [5].

\section{Post-buttoned device}

Although the results of the occlusion of PDAs $[4,16,17,25,26]$, ASDs [27-33], VSDs [22] and APW [5] with the buttoned device appear satisfactory and are truly comparable to the other devices [3437], following the completion of FDA-sponsored clinical trials, the inventor of the device decided not to seek pre-market approval (PMA) and, therefore, the device is no longer available for clinical use [38]. Consequently, the author uses Gianturco coils to occlude very small and small PDAs (Figures 7 and 8) and Amplatzer Duct Occluder (Figure 9), Amplatzer Duct Occluder II (Figure 10), and Amplatzer Vascular Plug (Figure 11) for moderate to large PDAs.

\section{Conflict of interest}

The author has no potential conflict of interest in connection with this article. 


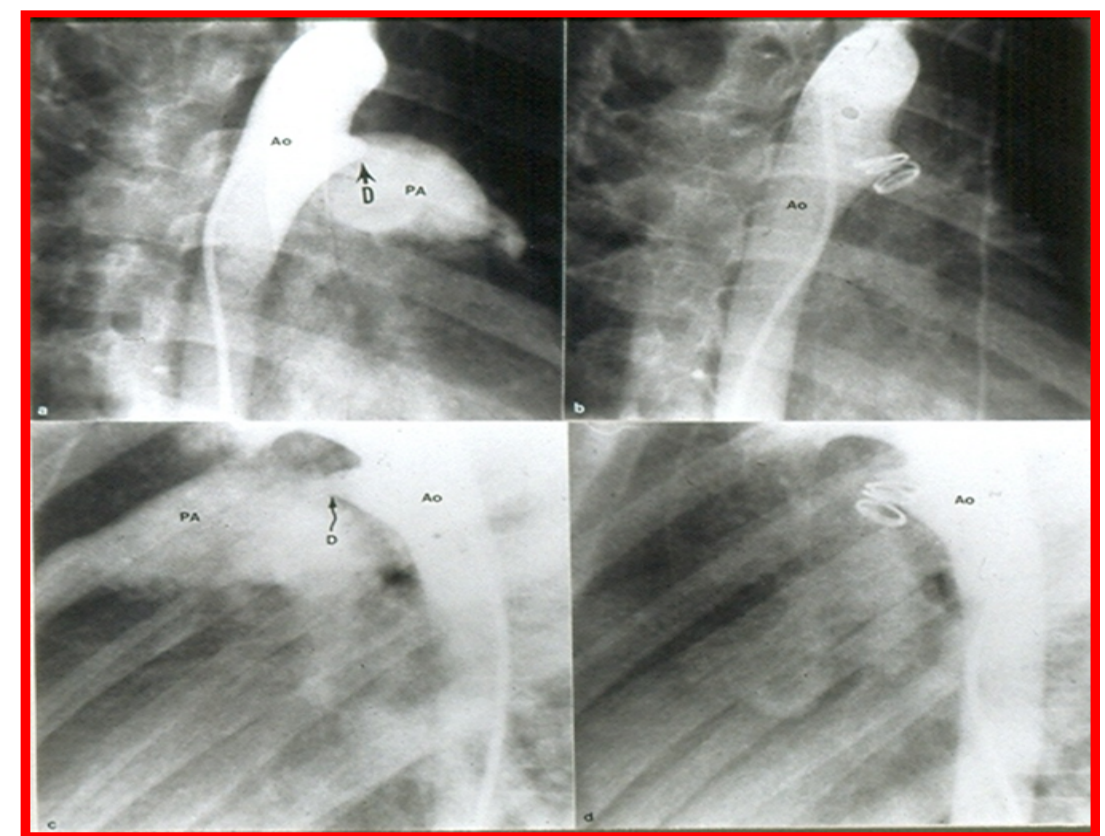

Figure 7. Selected cine frames from aortic arch angiograms in $30^{\circ}$ right anterior oblique (a and b) and straight lateral (c and d) views, showing a small to moderate sized ductus (D) before (a and c) and 15 minutes following (b and d) coil occlusion. Note the complete occlusion of the ductus in b and d. Ao, aorta; PA, pulmonary artery. Reproduced from Rao PS, et al., Am J Cardiol 1997; 80:1498-1501.

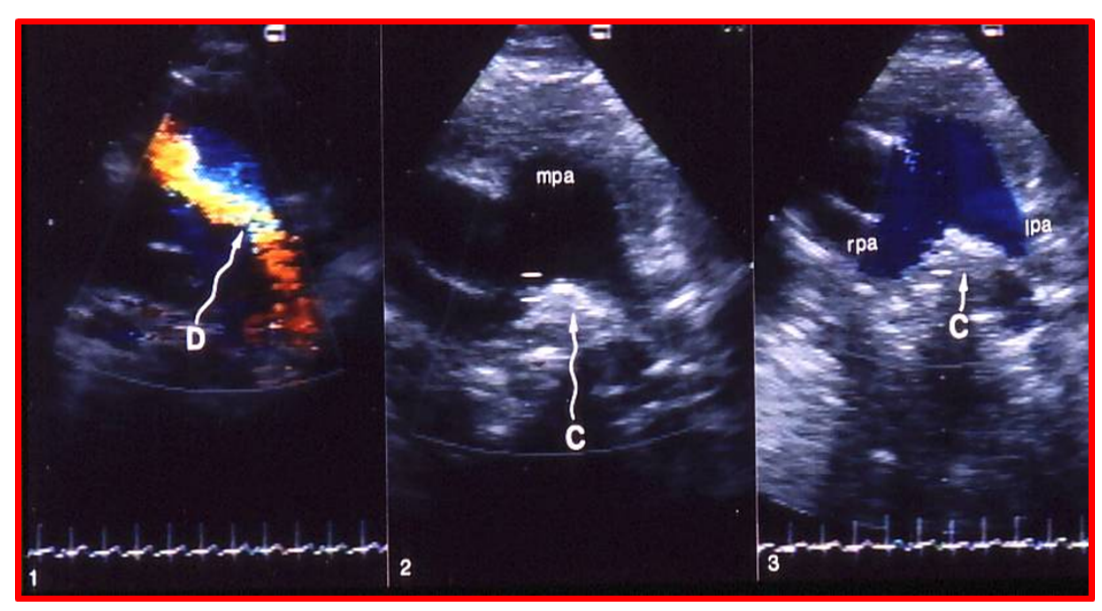

Figure 8. Selected video frames from echo-Doppler studies prior to (1) and following (2 \& 3 ) coil (C) occlusion of the patent ductus arteriosus (D). 1. Note the clear-cut visualization of the D by color. 2. An echo-bright structure, indicating the coil, in between the right (rpa) and left (lpa) pulmonary arteries at the expected location of ductal ampulla is seen. 3. Note the blue laminar flow in both the lpa and rpa, and that there is no color disturbance in the pulmonary artery, indicating the complete closure of the ductus.

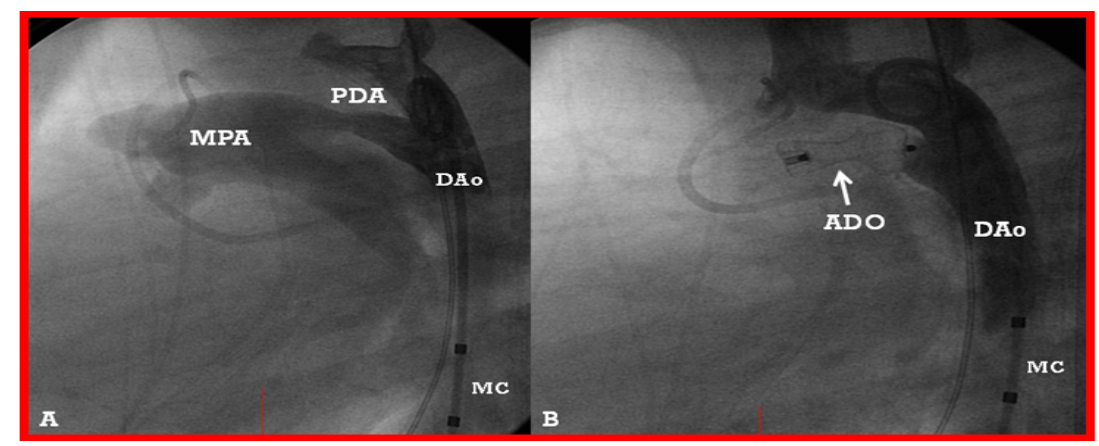

Figure 9. A. A selected cine frame from an aortic arch angiogram in lateral view, demonstrating a moderate-sized patent ductus arteriosus (PDA) opacifying the main pulmonary artery (MPA). B. Following the implantation of an Amplatzer duct occluder (ADO), no residual shunt is seen. Also, there is no descending aortic (DAo) obstruction. MC, Marker pigtail catheter. 


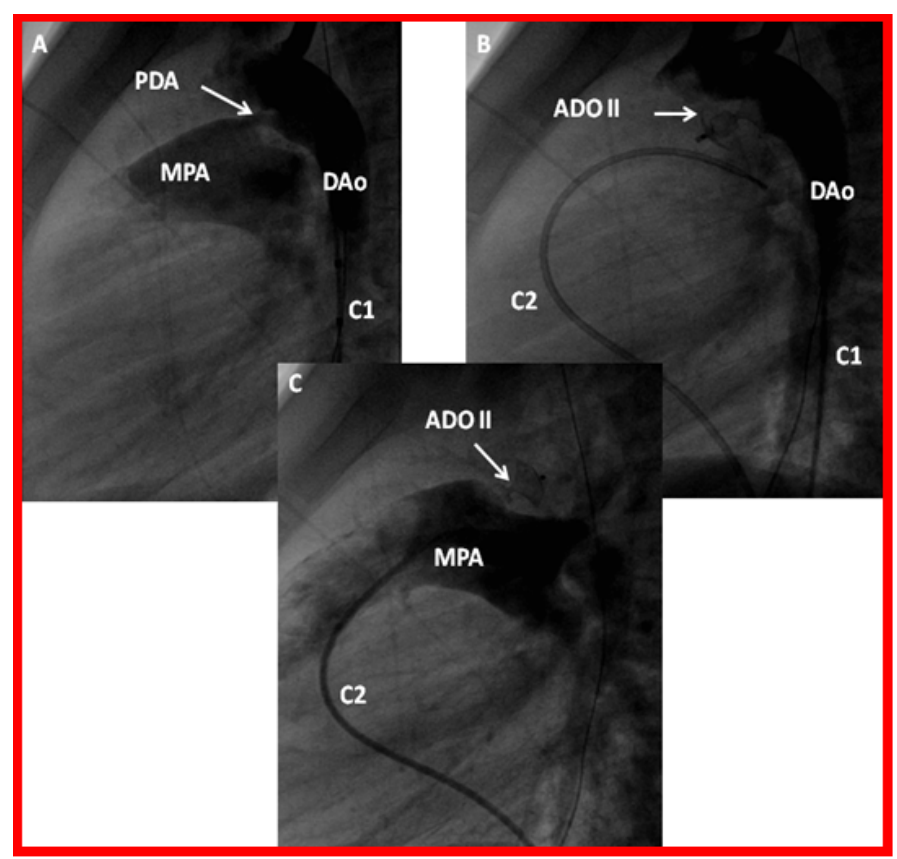

Figure 10. A. A selected cine frame from an aortic arch angiogram in lateral view, demonstrating a small-to-moderate patent ductus arteriosus (PDA) (arrow). B. Following the implantation of an Amplatzer duct occluder II (ADO II) (arrow), an aortic arch angiogram shows a good device position with no residual shunt. Also note that there is no obstruction in the descending aorta (DAo). C. A main pulmonary artery (MPA) cineangiographic frame in lateral view, demonstrating a good position of the device without obstruction of the pulmonary artery. $\mathrm{C} 1$, catheter in the aorta; $\mathrm{C} 2$, catheter in the pulmonary artery.

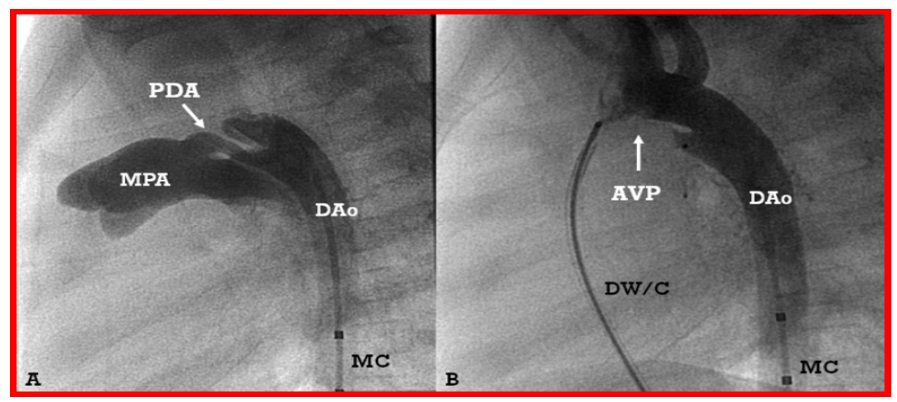

Figure 11. A. Selected cine frame from an aortic arch angiogram in lateral view, demonstrating a tubular patent ductus arteriosus (PDA). B. An Amplatzer vascular plug (AVP) was positioned across the PDA; note that there is complete occlusion of the PDA with no residual shunt. DAo, descending aorta; DW/C, delivery wire/catheter; $\mathrm{MC}$, marker pigtail catheter; MPA, main pulmonary artery.

\section{References}

1. Lochan R, Rao PS, Samal AK, Khanna AR, Mani GK, et al. (1994) Transcatheter closure of patent ductus arteriosus with an adjustable buttoned device in an adult patient. Am Heart $J$ 127: 941-943. [Crossref]

2. Rao PS, Ende DJ, Wilson AD, Smith PA, Chopra PS (1995) Follow-up results of transcatheter occlusion of atrial septal defect with buttoned device. Canad J Cardiol 11: 695-701. [Crossref]

3. Ende DJ, Chopra PS, Rao PS (1996) Transcatheter closure of atrial septal defect or patent foramen ovale with the buttoned device for prevention of recurrence of paradoxic embolism. Am J Cardiol 78: 233-236. [Crossref]

4. Rao PS, Kim SH, Rey C, Onorato E, Sideris EB (1998) Results of transvenous buttoned device occlusion of patent ductus arteriosus in adults. Am J Cardiol 82: 827-829. [Crossref]

5. Jureidini SB, Spadaro JJ, Rao PS (1998) Successful trans-catheter closure with the buttoned device of aortopulmonary window in an adult. Am J Cardiol 81: 371-372. [Crossref]
6. Rao PS, Palacios IF, Bach RG, Bitar SR, Sideris EB (2001) Platypnea-orthodeoxia syndrome: Management by trans-catheter buttoned device implantation. Cathe Cardiovasc Intervent 54: 77-82. [Crossref]

7. Bitar S, Rao PS. Platypnea-orthodeoxia syndrome: Transcatheter management. In Rao PS, Kern MJ. (editors) Catheter Based Devices for Treatment of Noncoronary Cardiovascular Disease in Adults and Children. Lippincott, Williams \& Wilkins, Philadelphia, PA, 2003:129-132. Chapter 15.

8. Rao PS (2004) Transcatheter management of platypnea-orthodeoxia syndrome. $J$ Invasive Cardiol 16: 583-584. [Crossref]

9. Rao PS (2009) Focus: Atrial septal defects, Structural heart disease in adults (Editorial). J Invasive Cardiol 21: A6-A10. [Crossref]

10. Rao PS (2009) When and how should atrial septal defects be closed in adults. J Invasive Cardiol 21: 76-82. [Crossref]

11. Rao PS (2012) Why, when and how should atrial septal defects be closed in adults. In: Rao PS, editor, Atrial Septal Defect, ISBN 978-953-51-0531-2; InTech, Rijeka, Croatia, pp: 121-138

12. Rao PS (2013) What an Adult Cardiologist Should Know about Cyanotic Congenita Heart Disease? J Cardiovasc Dis Diagn 1:1.

13. Rao PS. (2014) What the Adult Cardiologist Should Know About Cyanotic Congenital Heart Disease. In: Chopra HK, et al. (Eds), State of Art CSI Cardiology Update 2014.

14. van der Bom T, Bouma BJ, Meijboom FJ, Zwinderman AH, Mulder BJM (2012) The prevalence of adult congenital heart disease, results from a systematic review and evidence based calculation. Am Heart J 164: 568-575. [Crossref]

15. Sideris EB, Sideris SE, Ehly RL (1990) Occlusion of patent ductus arteriosus in piglet by a double disk self-adjustable device (Abstract). $J$ Am Coll Cardiol 15: 240A.

16. Rao PS, Wilson AD, Sideris EB, Chopra PS (1991) Transcatheter closure of patent ductus arteriosus with buttoned device: First successful clinical application in a child. Am Heart J 121: 1799-1802. [Crossref]

17. Rao PS, Sideris EB, Haddad J, Hausdorf G, Wilson AD, et al. (1993) Transcatheter occlusion of patent ductus arteriosus with adjustable buttoned device: Initial clinical experience. Circulation 88: 1119-1126. [Crossref]

18. Krichenko A, Benson L, Burrows P, Möes CA, McLaughlin P, et al. (1989) Angiographic classification of the isolated persistently patent ductus arteriosus and implications for percutaneous catheter occlusion. Am J Cardiol 63: 887-889. [Crossref]

19. Sideris EB, Sideris SE, Thanopoulos BD, Ehly RL, Fowlkes JP (1990) Transvenous atrial septal defect occlusion by the buttoned device. Am J Cardiol 66: 1524-1526. [Crossref]

20. Rao PS, Wilson AD, Chopra PS (1992) Transcatheter closure of atrial septal defect by "buttoned" devices. Am J Cardiol 69: 1056-1061. [Crossref]

21. Rao PS, Sideris EB, Hausdorf G, Rey C, Lloyd TR, et al. (1994) International experience with secundum atrial septal defect occlusion by the buttoned device. $\mathrm{Am}$ Heart J 128: 1022-1035. [Crossref]

22. Sideris EB, Haddad J, Rao PS (2001) The role of the 'Sideris' devices in the occlusion of ventricular septal defects. Current Intervent Cardiol Reports 3: 349-353.

23. Stamato T, Benson LN, Smallhorn JF, Freedom RM (1995) Transcatheter closure of an aortopulmonary window with a modified double umbrella occluder system. Cathet Cardiovasc Diagn 35: 165-167. [Crossref]

24. Tulloh RM, Rigby ML (1997) Transcatheter umbrella closure of aorto-pulmonary window. Heart 77: 479-480. [Crossref]

25. Rao PS, Sideris EB (1996) Transcatheter closure of patent ductus arteriosus: State of the art. J Invasive Cardiol 8: 278-288.

26. Rao PS, Kim SH, Choi J, Rey C, Haddad J, et al. (1999) Follow-up results of transvenous occlusion of patent ductus arteriosus with buttoned device. $J$ Am Coll Cardiol 33: 820-826. [Crossref]

27. Lloyd TR, Rao PS, Beekman RH III, Mendelsohn AM, Sideris EB (1994) Atrial septal defect occlusion with the buttoned device: A multi-institutional U.S. trial. Am J Cardiol 73: 286-291. [Crossref]

28. Zamora R, Rao PS, Lloyd TR, Beekman RH III, Sideris EB (1998) Intermediate-term results of Phase I FDA Trials of buttoned device occlusion of secundum atrial septal defect. J Am Coll Cardiol 31: 674-676. [Crossref]

29. Sideris EB, Rao PS (1996) Transcatheter closure of atrial septal defects: Role of buttoned devices. J Invasive Cardiol 8: 289-296. [Crossref] 
30. Rao PS, Berger F, Rey C, Haddad J, Meier B, et al. (2000) Results of transvenous occlusion of secundum atrial septal defects with $4^{\text {th }}$ generation buttoned device: Comparison with $1^{\text {st }}$, $2^{\text {nd }}$ and $3^{\text {rd }}$ generation devices. J Am Coll Cardiol 36: 583-592. [Crossref]

31. Rao PS, Sideris EB (2001) Centering-on-demand buttoned device: Its role in transcatheter occlusion of atrial septal defects. J Intervent Cardiol 14: 81-89. [Crossref]

32. Rao PS, Sideris EB (1998) Buttoned device closure of the atrial septal defect. $J$ Intervent Cardiol 11: 467-484

33. Rao PS (2003) Buttoned device. In: Rao PS, Kern MJ. (editors) Catheter Based Devices for Treatment of Noncoronary Cardiovascular Disease in Adults and Children. Lippincott, Williams \& Wilkins, Philadelphia, PA, 17-34.

34. Rao PS (2000) Summary and comparison of atrial septal defect closure devices. Current Intervent Cardiol Reports 2: 367-376.
35. Rao PS (2003) Comparative summary of atrial septal defect occlusion devices. In Rao PS, Kern MJ. (editors) Catheter Based Devices for Treatment of Noncoronary Cardiovascular Disease in Adults and Children. Lippincott, Williams \& Wilkins, Philadelphia, PA, 91-101, Chapter 11.

36. Rao PS (2001) Summary and comparison of patent ductus arteriosus closure devices. Current Intervent Cardiol Reports 3: 268-274. [Crossref]

37. Rao PS (2003) Summary and comparison of patent ductus arteriosus closure methods, In: Rao PS, Kern MJ. (editors) Catheter Based Devices for Treatment of Noncoronary Cardiovascular Disease in Adults and Children. Lippincott, Williams \& Wilkins, Philadelphia, PA, 219-228. Chapter 25.

38. Rao PS (2020) Atrial septal defects. In: Rao PS. Pediatric Cardiology: How It Has Evolved Over the Last 50 Years. Cambridge Scholars Publishing, New Castle upon Tyne, 321-386.

Copyright: $\odot 2020$ Rao PS. This is an open-access article distributed under the terms of the Creative Commons Attribution License, which permits unrestricted use, distribution, and reproduction in any medium, provided the original author and source are credited. 